\title{
Regulating Flowering and Extension Growth of Poinsettia Using Red and Far-red Light-emitting Diodes for End-of-day Lighting
}

\author{
Mengzi Zhang ${ }^{1}$ and Erik S. Runkle ${ }^{2}$ \\ Department of Horticulture, 1066 Bogue Street, Michigan State University, \\ East Lansing, MI 48824
}

Additional index words. Euphorbia pulcherrima, LEDs, light quality, photomorphogenesis, photoperiod, phytochrome

\begin{abstract}
Manipulating light quality is a potential alternative method of regulating plant height in the commercial production of ornamental crops. In particular, end-of-day (EOD) lighting with a high red $(R ; 600-700 \mathrm{~nm})$ to far-red (FR; 700-800 $\mathrm{nm}$ ) ratio (R:FR) can suppress extension growth, whereas a low $R: F R$ can promote it. We investigated the effects of the R:FR and duration of EOD lighting in regulating extension growth and flowering of two poinsettia cultivars, White Glitter and Marble Star. Plants were grown at $20^{\circ} \mathrm{C}$ under 9-hour days with or without EOD lighting provided by two types of lightemitting diode bulbs: $R+$ white+FR (subsequently referred to as $R+F R$ ) and FR only. The R:FR ratios were 0.73 and 0.04 , respectively, and the photon flux density between 400 and $800 \mathrm{~nm}$ was adjusted to 2 to $3 \mu \mathrm{mol} \cdot \mathrm{m}^{-2} \cdot \mathrm{s}^{-1}$ at plant canopy. The six EOD lighting treatments were R+FR or FR for 2 or 4 hours, 2 hours of R+FR followed by 2 hours of FR, and 4 hours of R+FR followed by 2 hours of FR. We also investigated the impact of a 4 hour moderate-intensity $\left(13 \mu \mathrm{mol} \cdot \mathrm{m}^{-2} \cdot \mathrm{s}^{-1}\right)$ EOD FR treatment in the second replication. EOD lighting generally increased poinsettia extension growth, with the greatest promotion under the longest lighting periods. There were no differences in days to first bract color and days to anthesis when the 9-hour day was extended by 2 hours, but flowering was delayed under 4- or 6-hour EOD treatments, except for the 2-hour R+FR + 2-hour FR and 4-hour FR treatments. Four hours of moderate-intensity EOD FR greatly promoted extension growth and delayed or prevented bract coloration in both cultivars. We conclude that EOD lighting promotes extension growth of poinsettia, and specifically, EOD FR at a low intensity $\left(2-3 \mu \mathrm{mol} \cdot \mathrm{m}^{-2} \cdot \mathrm{s}^{-1}\right)$ is not perceived as long-day signal, whereas a higher intensity $\left(13 \mu \mathrm{mol} \cdot \mathrm{m}^{-2} \cdot \mathrm{s}^{-1}\right)$ of $\mathrm{FR}$ delays flowering.
\end{abstract}

Poinsettia (Euphorbia pulcherrima) is a popular potted flowering crop, especially for the Christmas holiday, because of its colorful and showy bracts. Approximately one-third of the global poinsettia market is in the United States, whereas the remaining market is mostly in Europe (Taylor et al., 2011). Poinsettia was the second most valuable potted flowering plant after orchids in 2015, accounting for $\$ 140$ million in wholesale sales and representing $17 \%$ of the total value of potted flowering plants sold in the United States (U.S. Department of Agriculture, 2016). Coordinated control of flowering of poinsettia is crucial so that commercial crops are

Received for publication 2 Oct. 2018. Accepted for publication 14 Dec. 2018.

We gratefully acknowledge the U.S. Department of Agriculture (USDA)-Agricultural Research Service Floriculture and Nursery Research Initiative and Philips Lighting for supporting this project, C. Raker \& Sons and Syngenta Flowers for the donation of plant material, and Nate DuRussel for technical assistance. This work was supported by the USDA National Institute of Food and Agriculture, Hatch project 192266.

${ }^{1}$ Former graduate research assistant.

${ }^{2}$ Corresponding author. E-mail: runkleer@msu.edu marketable for predetermined dates for the Christmas holiday. It is a short-day (SD) plant (SDP) with a critical photoperiod of $\approx 12 \mathrm{~h}$ and $20 \mathrm{~min}$ (night length of $11 \mathrm{~h}$ and $40 \mathrm{~min}$ ), and thus is naturally induced to flower in the northern hemisphere beginning in late September (Ecke et al., 2004).

Height control is one of the major challenges in commercial greenhouse production of poinsettias. High-quality poinsettia requires the plants to be marketed at specific target heights, which is typically 36 to $41 \mathrm{~cm}$ for plants grown in 15-cm containers (Taylor et al., 2011). Excessively tall poinsettias can develop branches that are more susceptible to breakage and increase transportation costs (Clifford et al., 2004). Therefore, plant growth retardants are commonly used to suppress stem extension to produce more compact plants. Chlormequat chloride, daminozide, uniconazole, paclobutrazol, and flurprimidol, used as a substrate drench and/or foliar spray, are effective at inhibiting stem elongation (Currey and Lopez, 2011; Latimer and Whipker, 2013; Lopez and Runkle, 2007).

For ornamentals, although the promotion of stem growth is usually not desired in commercial production, it can be beneficial in some situations, such as in cut flower production or when plants are shorter than desired. Gibberellic acid is commonly applied by commercial growers to increase plant height and promote leaf expansion of poinsettia when an excessive concentration of a plant growth retardant was previously applied (Lopez and Runkle, 2007); however, the use of growth-regulating chemicals is restricted to various degrees by different governments (Rajapakse et al., 1999). Different strategies can be used as an alternative way to promote extension growth, such as a warmer day than night temperature, greater planting density (i.e., less spacing), and avoidance of phosphorus deficiency (Ecke et al., 2004; Runkle, 2005).

Light quality manipulation is an alternative strategy to manage plant height, especially the ratio of $\mathrm{R}(600-700 \mathrm{~nm})$ and FR $(700-800 \mathrm{~nm})$ radiation. $\mathrm{R}$ and $\mathrm{FR}$ radiation are perceived by phytochrome photoreceptors, which have two forms: an R light-absorbing (Pr) form and an FR light-absorbing (Pfr) form (Butler et al., 1959). The interconversion between these two forms of each phytochrome in plants is known as photoreversibility and can at least partially regulate seed germination, extension growth, and flowering (Borthwick and Downs, 1964; Borthwick et al., 1952; Schopfer et al., 1982). Spectral filters have been used experimentally to determine the effects of different light qualities on plant height. For example, poinsettias were grown under cladding materials of neutral density (control) $(\mathrm{R}: \mathrm{FR}=1.07)$ or $\mathrm{FR}$, $\mathrm{R}$, and blue (400-500 nm) plastic filters, creating an FR-deficient, R-deficient, and blue-deficient environment with an R:FR of $1.74,0.04$, and 1.05 , respectively, under sunlight (Clifford et al., 2004). The internode lengths were increased by $71 \%$ and $9 \%$ under R- and blue-deficient filters, respectively, and decreased by $20 \%$ under the FR-deficient filter compared with the control.

EOD lighting also can be used to regulate extension growth by manipulating the R:FR ratio. Generally, plants elongate under a low R:FR ratio. For example, chrysanthemum (Chrysanthemum $\times$ morifolium) was grown under a 9-h SD with EOD lighting for $30 \mathrm{~min}$ at a photosynthetic photon flux density (PPFD) of 1 to $3 \mu \mathrm{mol} \cdot \mathrm{m}^{-2} \cdot \mathrm{s}^{-1}$ with either a high (2.4) or low (0.4) R:FR (Lund et al., 2007). Plant height after 3 weeks increased by $50 \%$ to $75 \%$ with EOD lighting at the low R:FR compared with the high ratio. In a separate study, impatiens (Impatiens walleriana), geranium (Pelargonium $\times$ hortorum), and petunia (Petunia $\times$ hybrida) were grown under an 8.5-h day with $30 \mathrm{~min}$ of EOD lighting at $20 \mu \mathrm{mol} \cdot \mathrm{m}^{-2} \cdot \mathrm{s}^{-1}$ with an R:FR of 0.9 or 8.4 (Randall, 2014). Stem length of impatiens, geranium, and petunia was promoted by $29 \%, 20 \%$, and $44 \%$, respectively, after $21 \mathrm{~d}$ under the lower R:FR compared with the higher ratio.

EOD lighting also can be used to extend the natural photoperiod and create long days to regulate flowering of photoperiodic crops. The threshold irradiance to regulate flowering of several herbaceous perennials ranged from 0.05 
to $0.4 \mu \mathrm{mol} \cdot \mathrm{m}^{-2} \cdot \mathrm{s}^{-1}$, whereas the saturation irradiance ranged from 0.2 to $1.0 \mu \mathrm{mol} \cdot \mathrm{m}^{-2} \cdot \mathrm{s}^{-1}$, depending on the species (Whitman et al., 1998). Generally, an intensity of 1 to 3 $\mu \mathrm{mol} \cdot \mathrm{m}^{-2} \cdot \mathrm{s}^{-1}$ is recommended to accelerate flowering of long-day plants (LDPs) and inhibit flowering of SDPs (Runkle, 2015).

$\mathrm{R}$ light is typically effective at inhibiting flowering of SDPs. For example, the flowering of chrysanthemum, dahlia (Dahlia hortensis), and marigold (Tagetes erecta) was delayed by 42,11 , and 10 to $20 \mathrm{~d}$ when grown under 4-h night interruption (NI) provided by light-emitting diodes (LEDs) with an R:FR $\geq 0.66$ at a photon flux density of 1.3 to 1.6 $\mu \mathrm{mol} \cdot \mathrm{m}^{-2} \cdot \mathrm{s}^{-1}$ compared with SD control (Craig and Runkle, 2013). The inclusion of FR with $\mathrm{R}$ radiation, delivered as EOD or NI lighting, had little to no effect on regulating flowering of SDPs, but did promote flowering of some LDPs. However, a low intensity of FR alone as an NI is generally not perceived as a long-day signal by LDPs and SDPs. For example, the SDP marigold flowered 10 to 19 d earlier under SDs or NI with only FR compared with NI with a combination of $\mathrm{R}$ and FR (Craig and Runkle, 2013).

$\mathrm{R} / \mathrm{FR}$ photoreversibility is one of the characteristic features for phytochrome responses and was first discovered in a lettuce (Lactuca sativa) seed germination experiment (Borthwick et al., 1952). R light promoted lettuce seed germination, whereas subsequent FR inhibited it. This kind of photoreaction response was also established on flower initiation of some model plants. For example, a short period of $\mathrm{R}$ light as an NI prevented the flower initiation of the SDPs soybean (Glycine max) and pigweed (Amaranthus caudatus) and induced the flowering of the LDP henbane (Hyoscyamus niger), whereas subsequent FR irradiation reversed the effects of R light (Downs, 1956). Although there are three action modes for phytochrome responses, photoreversibility is a characteristic of low-fluence response (Li et al., 2011). This suggests that phytochrome-mediated flowering responses could be affected by the last NI lighting treatment and potentially show photoreversibility in at least some light-sensitive plants.

The objective of this study was to investigate whether EOD FR would promote extension growth without influencing flowering of poinsettia. We also wondered whether flowering could be inhibited by delivering FR after R, given the phytochrome photoreversibility response. We postulated that a low intensity of FR as EOD lighting would promote extension growth but not regulate flowering and thus could be used to increase plant height without influencing crop scheduling. We also speculated that ending EOD lighting with FR would at least partly reverse the effects of $\mathrm{R}$ light at inhibiting flowering.

\section{Materials and Methods}

Plant materials. Unrooted cuttings of two cultivars of poinsettia, 'White Glitter' and 'Marble Star', were obtained from C. Raker \&
Sons (Litchfield, MI) for replication 1 and Syngenta Flowers (Gilroy, CA) for replication 2. They were rooted at $23{ }^{\circ} \mathrm{C}$ under a 16-h day in a propagation greenhouse at Michigan State University (East Lansing, MI). Rooted cuttings were transplanted into $15-\mathrm{cm}$ pots containing $70 \%$ peatmoss, $21 \%$ perlite, and $9 \%$ vermiculite potting media (SUREMIX; Michigan Grower Products, Inc., Galesburg, MI) and grown in a glassglazed greenhouse. All plants were grown under a 16-h photoperiod consisting of natural daylengths with supplemental lighting at a $P P F D$ of $70 \mu \mathrm{mol} \cdot \mathrm{m}^{-2} \cdot \mathrm{s}^{-1}$ provided from 400 W high-pressure sodium fixtures (LR48877; P.L. Light System, Beamsville, Ontario, Canada) for replication 1 or $\mathrm{R}+$ white LEDs $(210 \mathrm{~W}$, peak wavelength $=660 \mathrm{~nm}$; GreenPower LED top lighting DR/W/MB; Philips, Eindhoven, the Netherlands) for replication 2, from transplanting until the start of treatments. Supplemental lighting was automatically switched on when the outside ambient solar PPFD was $<437 \mu \mathrm{mol} \cdot \mathrm{m}^{-2} \cdot \mathrm{s}^{-1}$, as controlled by a greenhouse environmental control system (Integro 725; Priva North America, Vineland, Ontario, Canada). Plants were pinched back to six nodes from the soil surface $\approx 3$ weeks after transplanting. Approximately 4 weeks after pinching, 70 (replication 1) or 80 (replication 2) pots of the most uniform poinsettias of each cultivar were selected and randomly assigned to seven (replication 1) or eight (replication 2) benches with different lighting treatments in the same greenhouse. Plants were irrigated as necessary with reverse-osmosis water supplemented with a water-soluble fertilizer containing $\left(\mathrm{mg} \cdot \mathrm{L}^{-1}\right) 250 \mathrm{~N}, 25 \mathrm{P}, 239 \mathrm{~K}, 154 \mathrm{Ca}, 38 \mathrm{Mg}$, $3.4 \mathrm{Fe}, 0.8 \mathrm{Cu}, 0.8 \mathrm{Zn}, 1.7 \mathrm{Mn}, 0.4 \mathrm{~B}$, and $0.4 \mathrm{Mo}$ (electrical conductivity $=2.0$ ).

Lighting treatments. Ten plants of each cultivar were grown under a 9-h truncated natural day created by pulling the black cloth over each bench daily at $1700 \mathrm{HR}$ and opening it at $0800 \mathrm{HR}$. They received six (replication 1) or seven (replication 2) EOD lighting treatments or no EOD treatment (control). The EOD lighting treatments were delivered by R+white+FR LEDs (GreenPower DR/W/ FR flowering lamps; Philips) (subsequently referred to as R+FR) with an R:FR of 0.73 , and FR LEDs (GreenPower FR flowering lamps; Philips) with an R:FR of 0.04 (Fig. 1). The EOD lighting treatments were $2 \mathrm{~h}$ of $\mathrm{R}+\mathrm{FR}$ or FR (1700 HR to $1900 \mathrm{HR}), 2 \mathrm{~h}$ of R+FR followed by $2 \mathrm{~h}$ of FR (1700 HR to $1900 \mathrm{HR}+1900 \mathrm{HR}$ to $2100 \mathrm{HR}), 4 \mathrm{~h}$ of R+FR or FR (1700 HR to $2100 \mathrm{HR}$ ), and $4 \mathrm{~h}$ of R+FR followed by $2 \mathrm{~h}$ of FR (1700 HR to $2100 \mathrm{HR}+$ $2100 \mathrm{HR}$ to $2300 \mathrm{HR}$ ) (Table 1). Layers of wire mesh were placed over the lamps so that the average photon flux density (from 400 to $800 \mathrm{~nm}$ ) at plant canopy was between 2 and $3 \mu \mathrm{mol} \cdot \mathrm{m}^{-2} \cdot \mathrm{s}^{-1}$. In addition, $4 \mathrm{~h}$ of FR (1700 HR to $2100 \mathrm{HR}$ ) (subsequently referred to as H-FR) at 10 to $15 \mu \mathrm{mol} \cdot \mathrm{m}^{-2} \cdot \mathrm{s}^{-1}$ was provided as an additional treatment in replication 2. Photon flux measurements were made with a spectroradiometer (PS-200; StellerNet, Inc., Tampa, FL) at four representative positions $18 \mathrm{~cm}$

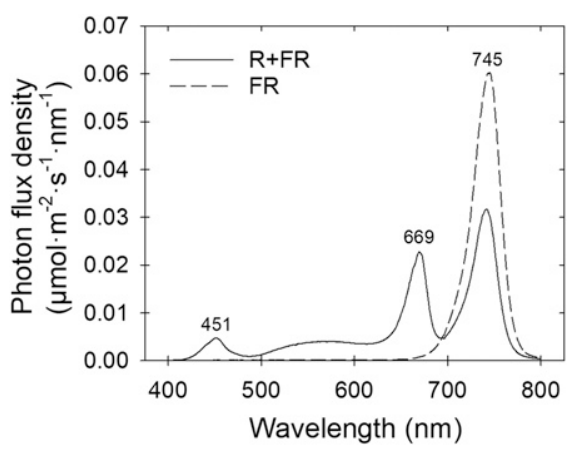

Fig. 1. Spectral distribution of two types of end-ofday (EOD) lighting treatments delivering red (R; 600 to $700 \mathrm{~nm}$ ) and/or far-red (FR; 700 to $800 \mathrm{~nm}$ ) radiation. The photon flux density of the two EOD lighting treatments was 2 to 3 $\mu \mathrm{mol} \cdot \mathrm{m}^{-2} \cdot \mathrm{s}^{-1}$.

above the bench. At the onset of treatments, the average photon flux density of the R+FR, $\mathrm{FR}$, and H-FR lighting treatments was 2.6, 2.5, and $13.4 \mu \mathrm{mol} \cdot \mathrm{m}^{-2} \cdot \mathrm{s}^{-1}$, respectively. These irradiance values at canopy height would have increased as the plants grew closer to the lighting fixtures, although actual values were not measured in time.

Environmental conditions. Plants were grown at a constant temperature set point of $20{ }^{\circ} \mathrm{C}$. Whitewash (Kool Ray Classic; Continental Products Co., Euclid, OH) was applied to the greenhouse glazing to deliver a more similar daily light integral between the two replications. The PPFD at bench height was recorded by a quantum sensor (LI-190SA; LI-COR, Lincoln, NE). Air temperature was recorded on benches by aspirated thermocouples (Type E; Omega Engineering, Stamford, $\mathrm{CT})$ near canopy height. Air temperature and the $P P F D$ were collected by a data logger (CR-10; Campbell Scientific, Logan, UT) every $10 \mathrm{~s}$ and average values were recorded hourly. Daily temperatures were checked routinely and the actual averages $( \pm \mathrm{SD})$ among treatments ranged from $19.4 \pm 1.4$ to $20.0 \pm 1.9$ in replication 1 and $21.5 \pm 3.1$ to $23.7 \pm 4.2$ in replication 2 . The average daily light integral during the study was 7.4 and $10.5 \mathrm{~mol} \cdot \mathrm{m}^{-2} \cdot \mathrm{d}^{-1}$ for replication 1 and 2, respectively.

Plant measurements. Plant height (from the substrate surface to the tallest meristem) was measured at the initiation of the lighting treatments. Height (from the substrate surface to the bottom of the flower bud) was measured at anthesis for flowering plants, and for nonflowering plants, height was recorded after 15 weeks of treatments. Date of first bract color (when the first leaf on each plant showed partial color), date of first anthesis (when the first flower showed pollen tubes), and node number were also recorded. Average internode length was calculated by final plant height divided by node number only in replication 2 .

Experimental design and data analysis. The experiment was performed twice, with treatments initiated in Oct. 2016 and Apr. 2017. The experiment was a randomized complete block design with subsamples. 
Two replications were considered two blocks to account for seasonal changes in environmental conditions. Each bench was regarded as the experimental unit for the EOD lighting treatment. Within the experimental unit, 10 individual plants per cultivar were the subsamples. Data were pooled from two replications and were analyzed with the SAS (SAS Institute, Inc., Cary, NC) mixedmodel (PROC MIXED) and glimmix-model (PROC GLIMMIX) procedures. Pairwise comparisons between treatments were performed with Tukey's honestly significant difference test at $P \leq 0.05$.

\section{Results}

All plants of both cultivars showed bract coloration and reached anthesis except for some plants under the 4-h R+FR, 4-h R+FR + 2-h FR, and 4-h H-FR treatments (Table 2). The general trends for bract coloration and anthesis were similar in both cultivars (Fig. 2). When the day was extended for $\leq 4$ h of lighting, days to first bract coloration and anthesis were similar to that of plants grown under the 9-h SD (control), except for plants under the 4-h R+FR treatment. The 4-h $\mathrm{R}+\mathrm{FR}$ delayed bract coloration and anthesis by 34 and $29 \mathrm{~d}$ in 'Marble Star' and 28 and $23 \mathrm{~d}$ in 'White Glitter', respectively, compared with the SD control, whereas the 4-h FR EOD did not delay flowering. In addition, the 4-h R+FR + 2-h FR and 4-h H-FR treatments delayed first bract coloration of 'Marble Star' by 45 and $55 \mathrm{~d}$ and anthesis by 34 and $38 \mathrm{~d}$, respectively, compared with the SD control. Similarly, in 'White Glitter', bract coloration and anthesis were delayed by 17 and $34 \mathrm{~d}$, respectively, under 4-h R+FR +2 -h FR EOD lighting. The days to bract coloration and anthesis were statistically similar under 4-h R+FR and 4-h R+FR + 2-h FR; therefore, no phytochrome photoreversibility was observed. Under the 4-h $\mathrm{R}+\mathrm{FR}+$ 2-h FR and 4-h H-FR lighting treatments, 'Marble Star' reached anthesis shortly after first bract coloration, and the interval was much shorter than for plants under the other lighting treatments.

Among the plants under treatments that fully flowered, stem length generally increased as the duration of light increased in both cultivars (Fig. 3). Plants of both cultivars were tallest under the longest EOD lighting treatment with a low-light intensity (4-h R+FR + 2-h FR). The increase in stem length at the end of the experiment for 'Marble Star' and 'White Glitter' was 161\% and $207 \%$ greater, respectively, under the longest EOD lighting compared with that of plants grown under the SD control. In addition, extension growth at anthesis of 'Marble Star' under the 4-h R+FR was $125 \%$ greater than that of the control. Stem elongation of 4h H-FR for 15 weeks was statistically similar to that of those under 4-h R+FR followed by 2-h FR. Therefore, $4 \mathrm{~h}$ of moderate-intensity FR was as effective as the 6-h EOD lighting treatment in increasing plant height, and thus

Table 1. Diagram of lighting treatments during an otherwise 15 -h dark period (black bar). Plants were grown under a 9-h day without or with end-of-day lighting from red+white+far-red (R+FR; white bar) or far-red (FR; grid bar) light-emitting diodes at 2 to $3 \mu \mathrm{mol} \cdot \mathrm{m}^{-2} \cdot \mathrm{s}^{-1}$. In replication 2 , an additional treatment of a moderate-intensity far-red $(\mathrm{H}-\mathrm{FR})$ at $13 \mu \mathrm{mol} \cdot \mathrm{m}^{-2} \cdot \mathrm{s}^{-1}$ was included.

\begin{tabular}{|c|c|}
\hline Lighting treatment & Lighting diagram \\
\hline None (control) & \\
\hline 2-h R+FR & \\
\hline 2-h FR & \\
\hline 2-h R+FR + 2-h FR & \\
\hline 4-h R+FR & \\
\hline 4-h FR & \\
\hline 4-h R+FR + 2-h FR & \\
\hline 4-h H-FR & \\
\hline
\end{tabular}

Table 2. Effect of end-of-day lighting treatments on the percentage of plants with bract color and reaching anthesis for two cultivars of poinsettia.

\begin{tabular}{|c|c|c|c|c|c|c|c|c|}
\hline \multirow[b]{3}{*}{ Lighting treatment } & \multicolumn{4}{|c|}{ Bract color } & \multicolumn{4}{|c|}{ Anthesis } \\
\hline & \multicolumn{2}{|c|}{ Rep 1} & \multicolumn{2}{|c|}{ Rep 2} & \multicolumn{2}{|c|}{ Rep 1} & \multicolumn{2}{|c|}{ Rep 2} \\
\hline & $\begin{array}{c}\text { Marble } \\
\text { Star }\end{array}$ & $\begin{array}{l}\text { White } \\
\text { Glitter }\end{array}$ & $\begin{array}{c}\text { Marble } \\
\text { Star }\end{array}$ & $\begin{array}{l}\text { White } \\
\text { Glitter }\end{array}$ & $\begin{array}{c}\text { Marble } \\
\text { Star }\end{array}$ & $\begin{array}{l}\text { White } \\
\text { Glitter }\end{array}$ & $\begin{array}{c}\text { Marble } \\
\text { Star }\end{array}$ & $\begin{array}{l}\text { White } \\
\text { Glitter }\end{array}$ \\
\hline None (control) & 100 & 100 & 100 & 100 & 100 & 100 & 100 & 100 \\
\hline 2-h R+FR & 100 & 100 & 100 & 100 & 100 & 100 & 100 & 100 \\
\hline 2-h FR & 100 & 100 & 100 & 100 & 100 & 100 & 100 & 100 \\
\hline 2-h R+FR + 2-h FR & 100 & 100 & 100 & 100 & 100 & 100 & 100 & 100 \\
\hline 4-h R+FR & 100 & 100 & 40 & 90 & 100 & 100 & 30 & 30 \\
\hline 4-h FR & 100 & 100 & 100 & 100 & 90 & 100 & 100 & 100 \\
\hline 4-h R+FR + 2-h FR & 80 & 100 & 30 & 40 & 50 & 80 & 20 & 20 \\
\hline$\underline{4-h \mathrm{H}-\mathrm{FR}^{\mathrm{z}}}$ & - & - & 40 & 20 & - & - & 30 & 0 \\
\hline
\end{tabular}

${ }^{\mathrm{z}}$ Performed only in Rep 2.

See Table 1 for treatment descriptions.

$\mathrm{FR}=$ far-red light; H-FR $=4 \mathrm{~h}$ of moderate-intensity far-red; $\mathrm{R}=$ red light; Rep = replication.

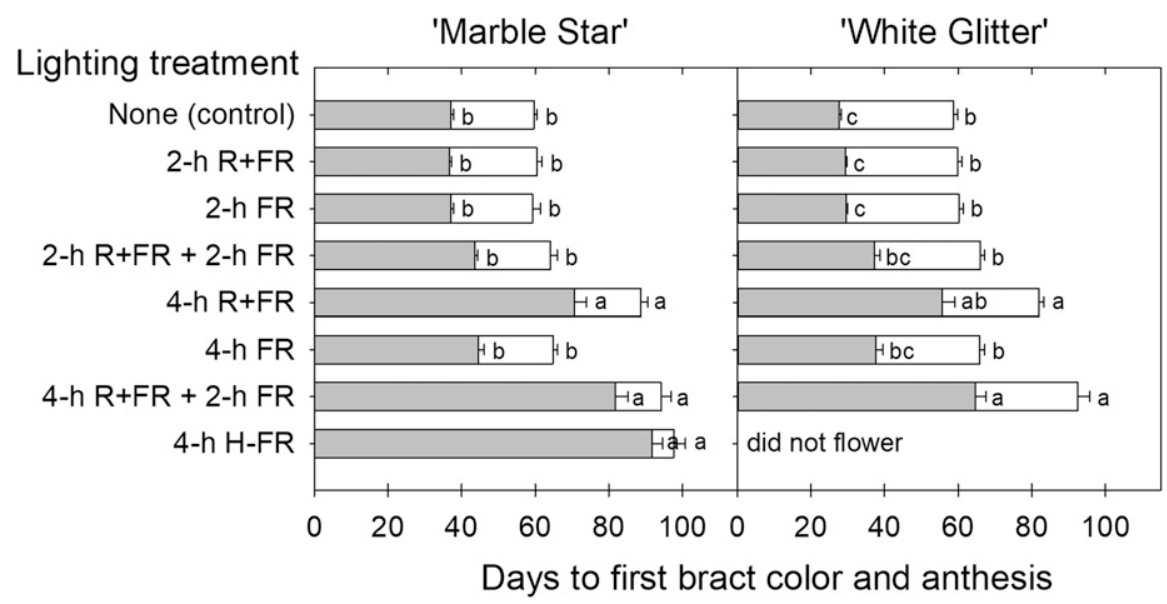

Fig. 2. Days to first bract color (gray bar) and anthesis (white bar) of two cultivars of poinsettia grown under a 9-h short-day (control) and seven red (R) and/or far-red (FR) end-of-day lighting treatments (see Table 1 for treatment descriptions). All data were pooled from two replications, except 4-h of moderate-intensity FR (H-FR), which was conducted only in the second replication. Pairwise comparison was made within each cultivar. Means sharing a letter are not statistically different by Tukey's honestly significant difference test at $P \leq 0.05$. Error bars indicate standard error.

these plants were also the tallest among all the lighting treatments.

'Marble Star' had an average of 14 or 15 nodes under all treatments 15 weeks after the initiation of the treatments, except for the 4-h R+FR, 4-h R+FR + 2-h FR, and 4-h H-FR treatments, which developed 20,20, and 27 nodes, respectively, before anthesis (Fig. 3). Similarly, 'White Glitter' had an average of 15 to 19 nodes overall but developed 6 and 9 more nodes under the 4-h R+FR + 2-h FR and 4-h H-FR treatments, respectively, compared with the SD control. Average internode length of most EOD lighting treatments was significantly greater than that of plants grown under the 9-h day. 'Marble Star' and 'White Glitter' grown under 2-h R+FR + 2-h FR developed a $22 \%$ and $19 \%$ longer internode, respectively, compared with that of those under 2-h R+FR. Similarly, 'White Glitter' developed a $21 \%$ greater internode length, respectively, when grown under 4-h R+FR + 

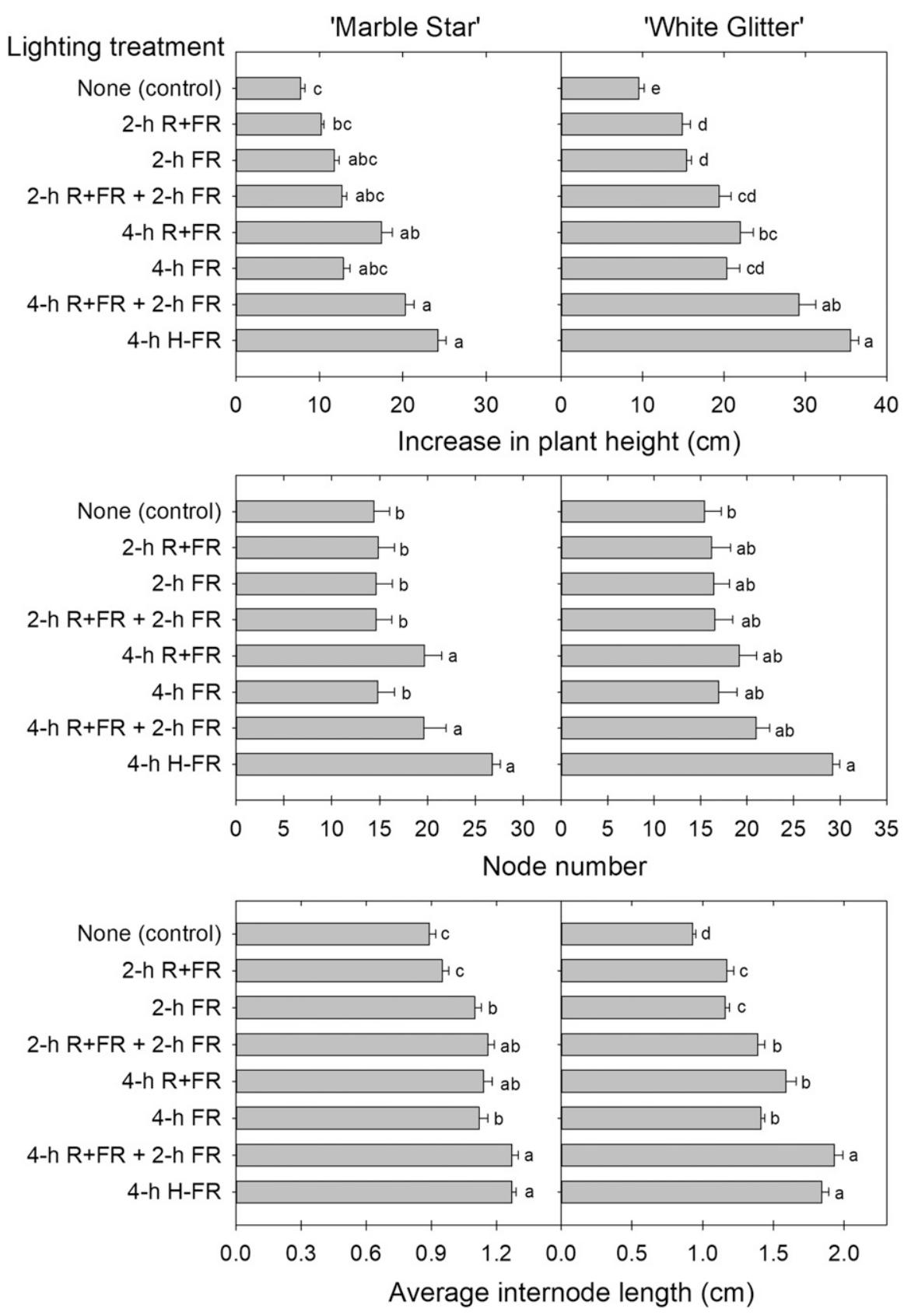

Fig. 3. Increase in plant height, node number, and average internode length of two cultivars of poinsettia grown under a 9-h short day (control) and seven end-of-day red (R) and/or far-red (FR) lighting treatments (see Table 1 for treatment descriptions). Pairwise comparisons were made within each cultivar. Means sharing a letter are not statistically different by Tukey's honestly significant difference test at $P \leq 0.05$. Error bars indicate standard error.

2-h FR compared with 4-h R+FR. In addition, the average internode length for both cultivars was significantly greater for plants under 4-h H-FR compared with 4-h FR, with a promotion of $13 \%$ in 'Marble Star' and 30\% in 'White Glitter'.

\section{Discussion}

We tested the hypothesis that flowering of the SDP poinsettia would not be influenced by delivery of FR light during an otherwise long night. With respect to flowering, several LDPs, including black-eyed Susan (Rudbeckia hirta) and fuchsia (Fuchsia hybrida), a low intensity of FR alone as EOD lighting was not perceived as a long-day signal in poinsettia, whereas a mixture of $\mathrm{R}$ and FR inhibited flowering.

The flowering percentage decreased in both cultivars when they were grown under 4-h EOD lighting of $13 \mu \mathrm{mol} \cdot \mathrm{m}^{-2} \cdot \mathrm{s}^{-1} \mathrm{FR}$ compared with that of the SD control. Days to first bract color and anthesis of 'Marble Star' were significantly delayed, and 'White Glitter' remained vegetative when the experiment ended. Therefore, FR alone as EOD lighting is less effective than when provided with $\mathrm{R}$ light for inhibiting flowering at a low intensity, but was surprisingly effective when provided at a moderate intensity. In contrast, Higuchi et al. (2012) grew the SDP chrysanthemum under cool-white fluorescent tubes at $150 \mu \mathrm{mol} \cdot \mathrm{m}^{-2} \cdot \mathrm{s}^{-1}$ for $12 \mathrm{~h}$ per day with or without a 4-h NI provided by either R or FR monochromatic LEDs. An FR NI of 62 $\mu \mathrm{mol} \cdot \mathrm{m}^{-2} \cdot \mathrm{s}^{-1}$ did not inhibit the flowering of chrysanthemum. These results suggest that the reproductive process of poinsettia is relatively sensitive to FR radiation, and even a moderate dose of FR $\left(13 \mu \mathrm{mol} \cdot \mathrm{m}^{-2} \cdot \mathrm{s}^{-1}\right.$ for 4 h) is sufficient to inhibit the flowering of poinsettia but perhaps not of other SDPs, such as chrysanthemum.

The critical photoperiod of poinsettia is $\approx 12 \mathrm{~h}$ and $20 \mathrm{~min}$ (Ecke et al., 2004). As expected, plants grown with $2 \mathrm{~h}$ of $\mathrm{R}+\mathrm{FR}$ EOD lighting, creating an 11-h photoperiod, flowered like those under the SD control. We also expected that the 2-h R+FR + 2-h FR EOD lighting treatment would create an SD because the low-intensity FR would not be perceived as a long-day signal, and, indeed, that was observed. Plants under the 4-h R+FR and 4-h R+FR + 2-h FR treatments (creating a 13- and 15-h photoperiod, respectively) flowered, although some plants did not flower in replication 2 and flowering was delayed. However, unlike plants under SD conditions, the primary stems of some plants grown under $\geq 4$-h EOD lighting remained vegetative, whereas bract color and anthesis occurred on lower branches that were at least partly shaded by the primary stems (data not collected). We postulate that the leaves on the primary stem prevented $\mathrm{R}$ light from reaching lower branches, and thus those branches were induced to flower.

The flowering of plants grown under 4-h $\mathrm{R}+\mathrm{FR}$ EOD lighting was delayed, and we did not observe a reversing effect of subsequent 2-h FR EOD lighting that one might expect with phytochrome photoreversibility. Phytochrome photoreversibility responses are reportedly low-fluence responses with saturating photon fluxes of up to $1000 \mu \mathrm{mol} \cdot \mathrm{m}^{-2}$ (Li et al., 2011). In this study, the total photon fluence of $\mathrm{R}$ light during one night was 11,500 to $17,500 \mu \mathrm{mol} \cdot \mathrm{m}^{-2}$, which exceeded the response saturation range. In addition, once receiving the $\mathrm{R}$ light, phytochrome would change from the biologically inactive Pr form to biologically active Pfr form. The Pfr transition action can vary from slow to fast in responses such as stem elongation, seed germination, and flower induction 
(Kendrick and Kronenberg, 2012). For example, the transition action can vary from $9 \mathrm{~h}$ of darkness between $\mathrm{R}$ and $\mathrm{FR}$ required for a $50 \%$ loss of photoreversibility in germination of lettuce seeds to 30-60 $\mathrm{min}$ before Pfr decreases and induces flowering of the SDP cocklebur (Xanthium strumarium) (Borthwick et al., 1954; Kendrick and Kronenberg, 2012; Salisbury, 1981). Therefore, $2 \mathrm{~h}$ of FR at a low fluence immediately after $\mathrm{R}$ may not be a sufficient dose to reverse the flowering inhibition by $4 \mathrm{~h}$ of $\mathrm{R}$ light.

Generally, plant height increased as the lighting duration increased, with the greatest promotion under the longest photoperiod or under the higher intensity of EOD FR lighting. Longer stems can result from longer internodes, more nodes because of the delay in the flower initiation, or both. Craig and Runkle (2013) reported that SDPs grown under NI with a moderate R:FR were taller than those grown under NI with FR alone because plants under FR-only NI entered the reproduction stage earlier in development. Similarly, chrysanthemum and marigold under 4-h NI that delayed flowering were significantly taller compared with those in the SD treatment (Meng and Runkle, 2015). In this study, both cultivars of poinsettia grown under 4-h FR initiated a flowering process similar to that of plants under the SD control, whereas flowering under 4-h R+FR, 4-h R+FR + 2-h FR, and 4-h H-FR was delayed and plants developed more nodes before flowering. Therefore, flower initiation was later in development and the overall extension of plants under those treatments was greater than that of the others.

Delivering low-intensity EOD FR successfully promoted poinsettia extension growth without delaying flowering. Promotion of stem length can be achieved by providing EOD lighting, and a low R:FR is typically more effective than a high one. For example, the hypocotyl length of tomato seedlings under 12-min EOD lighting treatment, regardless of light quality, was $20 \%$ to $44 \%$ greater than that without an EOD treatment (Chia and Kubota, 2010). In addition, the hypocotyl length under EOD lighting with an R:FR of 0.05 was $20 \%$ greater than under EOD lighting, with an R:FR of 0.47 . In another poinsettia study, two cultivars (Christmas Spirit and Christmas Eve) were exposed to R or FR EOD lighting for $30 \mathrm{~min}$ at $10 \mu \mathrm{mol} \cdot \mathrm{m}^{-2} \cdot \mathrm{s}^{-1}$ after a $10-\mathrm{h}$ SD (Islam et al., 2014). The internode length after 11 weeks was $55 \%$ to $107 \%$ greater under EOD-FR compared with EOD-R. In our study, plant height in 'Marble Star' under the 2-h EOD lighting treatments (regardless of light quality) was statistically similar to that of the SD control, whereas in 'White Glitter', plants were significantly taller. In addition, no differences in height and internode length were observed for both cultivars grown under 2- and 4-h EOD-FR compared with $\mathrm{R}+\mathrm{FR}$. Therefore, the sensitivity of response to the R:FR in stem elongation might be cultivar specific. This is supported by Rajapakse et al. (1993), who reported that a 15-min EOD-FR treatment did not influence plant height of one cultivar of chrysanthemum but increased height by $\approx 50 \%$ in another cultivar.

\section{Literature Cited}

Borthwick, H.A. and R.J. Downs. 1964. Roles of active phytochrome in control of flowering of Xanthium pensylvanicum. Bot. Gaz. 125:227231.

Borthwick, H.A., S.B. Hendricks, E.H. Toole, and V.K. Toole. 1954. Action of light on lettuceseed germination. Bot. Gaz. 115:205-225.

Borthwick, H.A., S.B. Hendricks, M.W. Parker, E.H. Toole, and V.K. Toole. 1952. A reversible photoreaction controlling seed germination. Proc. Natl. Acad. Sci. USA 38:662-666.

Butler, W.L., K.H. Norris, H.W. Siegelman, and S.B. Hendricks. 1959. Detection, assay, and preliminary purification of the pigment controlling photoresponsive development of plants. Proc. Natl. Acad. Sci. USA 45:1703-1708.

Chia, P.L. and C. Kubota. 2010. End-of-day far-red light quality and dose requirements for tomato rootstock hypocotyl elongation. HortScience 45:1501-1506.

Clifford, S.C., E.S. Runkle, F.A. Langton, A. Mead, S.A. Foster, S. Pearson, and R.D. Heins. 2004. Height control of poinsettia using photoselective filters. HortScience 39:383-387.

Craig, D.S. and E.S. Runkle. 2013. A moderate to high red to far-red light ratio from lightemitting diodes controls flowering of short-day plants. J. Amer. Soc. Hort. Sci. 138:167-172.

Craig, D.S. and E.S. Runkle. 2016. An intermediate phytochrome photoequilibria from nightinterruption lighting optimally promotes flowering of several long-day plants. Environ. Exp. Bot. 121:132-138.

Currey, C.J. and R.G. Lopez. 2011. Early flurprimidol drench applications suppress final height of four poinsettia cultivars. HortTechnology 21:35-40.

Downs, R.J. 1956. Photoreversibility of flower initiation. Plant Physiol. 31:279-284.

Ecke, III, P., J. Faust, A. Higgins, and J. Williams. 2004. The Ecke poinsettia manual. Ball Publ., Batavia, IL.

Higuchi, Y., K. Sumitomo, A. Oda, H. Shimizu, and T. Hisamatsu. 2012. Day light quality affects the night-break response in the shortday plant chrysanthemum, suggesting differential phytochrome-mediated regulation of flowering. J. Plant Physiol. 169:1789-1796.
Islam, M.A., D. Tarkowská, J.L. Clarke, D.R Blystad, H.R. Gislerød, S. Torre, and J.E. Olsen. 2014. Impact of end-of-day red and far-red light on plant morphology and hormone physiology of poinsettia. Scientia Hort. 174:7786.

Kendrick, R.E. and G.H. Kronenberg. 2012. Photomorphogenesis in plants. 2nd ed. SpringerVerlag, Berlin, Germany.

Latimer, J.G. and B. Whipker. 2013. Selecting and using plant growth regulators on floricultural crops. 20 Mar. 2017. <https://vtechworks. lib.vt.edu/bitstream/handle/10919/48109/ HORT-43P-pdf.pdf>.

Li, J., G. Li, H. Wang, and X. Wang Deng. 2011. Phytochrome signaling mechanisms. Arabidopsis Book 9:e0148.

Lopez, R.G. and E.S. Runkle. 2007. Early PGR drench applications on poinsettias. Greenhouse Product News 17(8):22-29.

Lund, J.B., T.J. Blom, and J.M. Aaslyng. 2007. End-of-day lighting with different red/far-red ratios using light-emitting diodes affects plant growth of Chrysanthemum $\times$ morifolium Ramat. 'Coral Charm'. HortScience 42:1609-1611.

Meng, Q. and E.S. Runkle. 2015. Investigating the efficacy of white light-emitting diodes at regulating flowering of photoperiodic ornamental crops. Acta Hort. 1170:951-958.

Rajapakse, N.C., M.J. McMahon, and J.W. Kelly. 1993. End of day far-red light reverses height reduction of chrysanthemum induced by $\mathrm{CuSO}_{4}$ spectral filters. Scientia Hort. 53:249-259.

Rajapakse, N.C., R.E. Young, M.J. McMahon, and R. Oi. 1999. Plant height control by photoselective filters: Current status and future prospects. HortTechnology 9:618-624.

Randall, W.C. 2014. Supplemental, end-of-day, and sole-source lighting from light-emitting diodes influences growth, morphology, and quality of annual bedding plant seedlings. Purdue Univ., West Lafayette, PhD Diss.

Runkle, E.S. 2005. Growing trends: How to increase plant height. Greenhouse Mgt. 25(8):74-77.

Runkle, E.S. 2015. Photoperiodic vs. photosynthetic lighting. Greenhouse Product News 25(9):74.

Salisbury, F.B. 1981. Twilight effect: Initiating dark measurement in photoperiodism of Xanthium. Plant Physiol. 67:1230-1238.

Schopfer, P., K.H. Fidelak, and E. Schäfer. 1982 Phytochrome-controlled extension growth of Avena sativa L. seedlings. Planta 154:224-230.

Taylor, J.M., R.G. Lopez, C.J. Currey, and J. Janick. 2011. The poinsettia: History and transformation. Chronica Hort. 51:23-28.

U.S. Department of Agriculture (USDA). 2016 Floriculture Crops 2015 Summary. Nat. Agr. Sta. Service, Washington, D.C. 13 Feb. 2018 $<$ http://usda.mannlib.cornell.edu/usda/current/ FlorCrop/FlorCrop-04-26-2016.pdf>.

Whitman, C.M., R.D. Heins, A.C. Cameron, and W.H. Carlson. 1998. Lamp type and irradiance level for daylength extensions influence flowering of Campanula carpatica 'Blue Clips', $\mathrm{Co}$ reopsis grandiflora 'Early Sunrise', and Coreopsis verticillata 'Moonbeam'. J. Amer. Soc. Hort. Sci. 123:802-807. 